\title{
Seeing Red
}

\section{Cuauhtémoc Medina}

\section{I: No more billboards!}

On Thursday 16 February 2012, Mexican President Felipe Calderón unveiled a peculiar mural relief, on the Mexican side of the Córdova de las Américas International Bridge that connects the American city of El Paso, Texas, with the most dangerous city on earth: Ciudad Juárez in the Mexican State of Chihuahua. The 8 metre by 21 metre billboard, written in English language like any good Latin American artwork, was not devoid of a self-reflective materiality. Purportedly made with three tonnes of metal from the destruction of illegal weaponry seized by the Mexican police and army, the work points towards a completely new genre: official postconceptual$i s m$. It is, in fact, text-based art with a message. President Calderon's mural (as he specified in the opening ceremony) makes a polite plea to the 'amigos' from the United States of America to stop the 'terrible violence' pervading Mexico by reducing their consumption of drugs and limiting the sale of assault weapons. ${ }^{1}$ Unless you count Hugo Chavez's antics as a contribution to the history of performance art, the mural suggests a remarkable moment of political expression, where a head of government feels the need to grant words a selfreflective materiality, somehow suggesting that the medium of politics (images and words) had been superseded by the weight and materiality of the current situation. This is the monumental text-based artwork devised by a southern nation state that seems to have surrendered the old fashioned means of diplomatic pressure, to turn to aesthetic means of persuasion, to turn the tautological ontology of image-text art into a political photo opportunity. For that sentence to acquire a monumental mass, it would imply that the words of Calderon 
have had to fall into a field of aesthetic uncertainty: the space of castrated speech.

One of the characteristics of billboards is that, besides being a surface to display a visual message, they block the view of the landscape. In fact, if we turn our view to other visual actions of the Calderon regime (2006-2012), like the colossal photographic images of idealised policemen that they have attached to certain public buildings in the cities, it will become apparent that the government wishes to cover the whole of the visual field. It was not until 2012 that the Mexican Government has tried to divert the attention of the media and the audience from the carnage of the so called 'Mexican Drug War' to the complicity of the United States as consumers and weapon providers. All in all, Calderon's turn to sculpture is related to the monumental failure of the main policy of his administration. In the 1990s, partly pushed by the US endorsement of the right wing paramilitary government of Colombia, the centre of gravity of the drug traffic in the Americas moved north. Economically, this meant that networks of distribution in Mexico have prevailed over the centres of production in the Andes. However, the turning point of the crisis of violence has to be credited to the intervention of the government. After officially winning with a minimum margin the polemical presidential election of July 2006, Felipe Calderón was about to become a weakened president. Just when he had assumed office, in December 2006, he declared war on drug traffickers, mobilising six thousand army troops to chase the so-called 'Familia' of the Michoacan State. Starting from that moment, Calderón deployed around forty-five thousand troops around the country, which rather than stopping violence have collaborated in its fantastic escalation. The death toll climbed steeply during the first year of Calderon's from 62 people killed in 2006 to 2477 in 2007 . Since then, the country has witnessed a geometrical progression of death and institutional failure. In November 2011 the administration admitted that more than forty-seven thousand people had been murdered both in the battles of the cartels and the operations of the Mexican police and army, turning this into one of the deadliest conflicts in the recent history of the continent. In January 2012 the administration refused to make any further casualty figures public, 
claiming such information was a matter of national security. The approaching presidential elections in the summer of 2012 may be one of the elements that have made such information suddenly so sensitive, conversely turning the current president vocal, for the first time, in begging Americans to cut down their legal and illegal chemical pleasures. But we ought to count also the outgoing administration's concern about its historical assessment, and the possibility that the figures that had been published until 2011 were, in reality, grossly underestimated. The Mexican drug war might have caused more than a hundred thousand victims in just six years, to become effectively the bloodiest conflict on earth at the beginning of the twenty-first century. ${ }^{2}$

Where to stand when the field of so-called 'poetic-politics' gets expanded not towards the poetical toolbox of activism, but in the aestheticisation of southern demagogy? Does the fact that a repressive right wing president turns to such means of expression put the legitimacy of contemporary artistic practices into question? Such was the conclusion that the so-called 'Comité Invisible Jaltenco' (Jaltenco Invisible Committee) arrived at when it commented on the case in an article that circulated both by email and the internet in February $2012 .{ }^{3}$ According to the committee - an anonymous art-critical entity that for a number of years has been chastising local contemporary art as entirely subservient to neoliberal politics - there are clear analogies to be traced between President Calderon's billboard and other 'situational' works by Mexican artists working 'within the sphere of symbolic and perceptual work towards a permanent design of information and creativity'. ${ }^{4}$ In the view of the Jaltenco Committee, works like Pedro Reyes's action Palas por pistolas (Shovels for pistols) that invite the population to 'turn weapons into shovels to plant trees' and suggest a turn towards development and production rather than destruction in crime infested cities like Culiacan (2008) or Juárez (2012), were akin to the president attempting to involve participatory practices into a 'condescending pedagogy' on the population. ${ }^{5}$ What troubled the committee was probably that both artist and government were agreed that weapons should be taken away from the hands of the civilians; however, their methodologies were not, in any form, similar. 
President Calderón did not indulge in any form of participatory work, nor did he intend to transform the values of the local population, as he was entirely focused on the gimmick of a foreign affairs gesture. One could put into question Pedro Reyes' claims that his work has social and climate benefit, and feel disturbed by the naive nature of his claims of raising 'awareness about gun and drug related violence both sides of the border', but corny as his politics are, they do not make a physical statement. Were we to compare the methodologies of the president's billboard with any other artwork, we would probably need to also discuss it against a work like Santiago Sierra's action of tracing the word Submission as a massive burning land art sign on the border (2008) which was, in fact, censored by the municipal authorities. ${ }^{6}$

Reyes's 'constructive spirit' is, indeed, corny and his social project dubious in kind. To claim that such a limited and moralistic exchange has a social pedagogical effect appears delusional, and the moral undertone of the whole operation, and its claim to transform violence into ecology, evades the economic, political and even gender structures behind the social tragedy of the place. Sierra's political commentary on the abject dependence of the Mexican policies unto the command from the American Empire seems to me to carry at least an outward critique. But beyond the relatively significant question of what is exactly the artistic moment of the president's work (either the seizure of weapons or the billboard itself), I think it is reasonable to say that, given the politicised nature of a significant amount of contemporary art imagery, we ought to be more intrigued by the fact that a head of state condescends to produce a sculpture of sorts, rather than in finding analogies between contemporary artworks and effective political forms. The mimetic character of most works involved in some kind of intervention aesthetics today implies that artists constantly refer to the media, codes and forms developed by any forms of political propaganda and action, even if, in purely chronological terms, here the politicians appear as belated newcomers in relation to the display of visual and symbolical gestures performed for years by artists and activists alike in the border region.

Notwithstanding Jaltenco's diagnosis of the alleged 
complicity of the (Mexican) art world with the neoliberal necropolitical project might be overstated, it is symptomatic of the disputed nature of the politics of art in the face of the latest Mexican butchery. It would appear there is a certain poetic friction (and theoretical agony) between works and words like the ones we are commenting on, precisely because, in a complicated way, contemporary art traverses the space of public opinion without necessarily accommodating its rules. Rather than subsuming all those cultural gestures to the late arrival of a president who, surprisingly, decided to modernise his rhetoric and aesthetic, we ought to entertain the possibility that (although marginally) contemporary artworks are not foreign to the space of representation and debates that shape the current crisis. Surely, that exposes the artists to fall into moments of both demagogy and opportunism. But it is only through taking that risk that they can pretend to be perceived as political well beyond the communication of their individual wishes and political leanings.

\section{II: The new south}

In 2009 Edgardo Aragon, a young artist born in 1985 in the Southern Mexican State of Oaxaca, made a sudden breakthrough into the contemporary art scene that accounts for more than just an individual, it represents an entire shift of class sensibilities. Despite the historical significance that the image of the peasant and the aesthetics of rural life have for the culture of postrevolutionary Mexico, and for the fabrication of stereotypes that the country exports, the realm of contemporary visual production and artistic practices is rarely accessible to the children of the countryside. The Mexican art world remains to a great extent - much like the casts of TV advertisements and soap operas - a preserve for the small white bourgeoisie of Mexico City and the cosmopolitan circuit that extends it. Thus, there is historical significance in the ways this enclave of cultural privilege is being put into question by the arrival of new geographies.

As has happened with literature and cinema, changing circumstances have forced the Mexican art world to expand to integrate different geographical belongings; somehow having to absorb the creative energy from both Tijuana and Sinaloa 
in the north, and the irruption of artists from the deep south. This window of opportunity for inclusion and decentralisation has had little to do with policies of inclusion and good will. No matter how much we hate to admit it, violence has always had a revolutionary role. The recent upsurge of violence produced since 2006 by the internal wars among the drug cartels and by their fight with the Mexican state has radically transformed the structures of living and production, as well as the identity of the subjects of a place and the codes, referents and issues that are assumed as part of the cultural imaginary of a historical moment. In an era defined by the media spectacle, the primary effect of violence is to sequester public opinion and attention. Thus it is undeniable that the generalisation of violence in Mexico over the past decade has forced a change in the visibility of the place.

In Efectos de familia/Family Effects (2010), Edgardo Aragon invited several of his cousins and nephews in the town of Otumba, Oaxaca, to re-enact before the camera a number of traumatic family stories. Presented as children's games of sorts, the videos appear more sinister as they are screened without any explicit commentary. Some of the works are extremely cryptic - a boy looking at a crumbled piece of paper floating on a river that he then folds into a small paper boat only to later attempt to sink it with rocks; a fight between two boys pretending to guard the barbed wire fence dividing two plots of land; a scene where one boy stops the advance of his SUV on a road several times until finally deciding to flee. The mystery of those actions rapidly dissipates when more familiar histories, easily graspable in Mexico's current context, begin to appear - a group of masked children armed with toy rifles shoot repeatedly at a boy sitting inside a van, reminding us of one of the most common execution methods or 'score settling' techniques employed by the cartels. Despite being veiled by the false innocence of children's games, Aragon's stories document a radical transformation of Oaxaca's imaginary and of its artistic production, moving them away from the mythological pretense of a primordial identity. What Aragon offers us instead is one of the most recent images of the south as it traverses the current phase of capitalist modernisation - a 
countryside that signals its own transformation in a terrain where poverty, power and resources are ardently contested.

Without a doubt this is a vision of the countryside marked by social and historical distance. After all, Aragon is a sociological exception - not only is he a young man who has had access to education but he has also participated in the complexly textured thought processes that encompass being trained as an artist. He also represents, as is usually the case with witnesses of a particularly dramatic historical moment, a certain exteriority to the processes he describes in his work. Being familiar with a situation, in both senses of the word, does not necessarily mean being immersed in its traps. It involves escaping that historical logic so that you yourself become a testament of a limited alternative in choosing to observe a social phenomenon rather than exemplifying it. Aragon and his family are, in that sense, surviving witnesses.

In his video Matamoros (2009), Aragon filmed the trajectory from his small dusty town of Otumba in the southern State of Oaxaca all the way to Mexico's northern border with the United States, following as closely as possible the route taken by Mr Pedro Vazquez Reyes in the 1980 s when he transported marijuana in a Volkswagen until he was caught by Mexican anti-narcotics police in the State of Tamaulipas. Vazquez Reyes was jailed for nearly a decade in the Matamoros penitentiary. The film is a travelogue through space and memory that shows both the beauty of the Mexican landscape and the military and police presence in the roads of the country. Following the voiceover narrative of Vazquez Reyes himself, we hear about his failed attempt to get a slice of the profits coming in from illegal trafficking. The work can hardly be accused of glamorising the narco lifestyle or of apologising for it. On the contrary, it operates as a different species of moral fable - the main character of the story is caught and beaten by the police and jailed for years far away from his family, hiding under a false identity. Aragon had very personal reasons for producing this complex representation of a criminal saga - Pedro Vazquez Reyes was the pseudonym of his father, who not only managed to survive and then share the experience of his imprisonment, but who was also wise 
enough to return to his hometown and separate himself from the gangs.

The radical element of this narrative is the way it exposes memories of the other rather than present the increasingly paranoid point of view of law enforcement that fuels hegemonic discourses. With delicacy, and avoiding macho gestures and bravado, Aragon echoes the tragedies and illusions of a peasanthood whose sole hope of social mobility lies in the production and trafficking of drugs. In Aragon's three-channel video installation La Trampa/The Trap (2011), the artist surveys the dry landscape of mountain ranges and ravines in his region, framing it through a makeshift landing strip. Halfway through the film, two men sing a corrido ballad that commemorates the 1979 massacre of several peasants who were killed by the federal police who discovered them harvesting marijuana. The burnt remains of a plane and the view of vultures and small planes flying over the ravines render the story with a material and contemporary referent that reinforces the centrality of those stories in understanding the current social crisis.

What Aragon's works put forward is an insight into the relationship between family histories and official histories and the way they both resonate and relate once they are articulated as some kind of contemporary myth. What emerges from his actions is, above all, a sense of urgency - the impossibility of understanding an artistic practice without addressing a zone of conflict or the intellectual labyrinths that are generated by it. What Aragon, in his own beautifully sparse, mythical, and poetic way portrays, is the fate of peasanthood in Latin America; the fate of a class whose seemingly redundant economic and social circumstances will not just pass by without the rest of us taking notice. In another video equally devoid of description and anecdotal intent, Aragon reinforces this idea through the representation of a mythological suicide. In Ley Fuga/Fugitive Law (2010) (a term that since the late nineteenth century has been used to describe the illegal executions performed by the police and the army when they claim that a prisoner tried to escape), Aragon presents an older man who takes off his shirt and then places it on a small raft that drifts on a stream only to later shoot at it a few times. 
Beyond the specific story that the video perhaps contains, the work alludes to the sacrificial wave currently passing through Mexico without a drop of sentimentalism; to the application of a cyclical death wish inscribed on the current era. Aragon's work is the extremely refined product of a broader social tragedy; a muted, discreet, and to a certain extent playful, presentation of a milieu that the artist is familiar enough with to disclose with an extraordinary level of ambivalence. This is the internal chronicle of an extremely important historical drama-one that traces the transformation of the countryside from a site imbued with the utopias of the Revolution to a new concentrated dystopia of the present.

At a time when the global economy increasingly divides the world population into two categories (those who are integrated into the maddening high speed circuit of overproduction and overconsumption, and those who are excluded from having access not only to basic conditions for survival, let alone the allure of consumption and exchange - the nomadic transnational urbanites and the ghosts of the slums), criminality appears as the only possibility, even if self-destructive, for the upward social mobility of the poor. The process of globalisation, inasmuch as it seeks to reduce entire populations to unemployment and dependency in order to offer nomadic capital ample cheap labour with which to colonise and recolonise vast territories, is bound to witness what Achille Mbembe aptly described as 'the creation of death worlds, new and unique forms of social existence in which vast populations are subjected to conditions of life conferring upon them the status of living dead'.7 In the geography of necropolitics - drug dealing, kidnapping, piracy, people trafficking, the enslavement of migrants and as has happened in Mexico recently, the privatisation of mass graves ${ }^{8}$ - the quest for excess is connected across social classes, both at the top and bottom, through methods that while different are still intimately connected to the consumerist cravings experienced both in the south and the north. The extreme impoverishment of the peasant populations of the south and the dissolution of their traditional communitarian ways of living produce a new kind of cheap labour that helps construct a living hell. The rapid impoverishment of the countryside, the forced 
integration of peasants into the market economy, and the cultural pressures of consumer capitalism have created a distinct marginal social class for whom criminality seems to be the only economically and psychologically rational alternative. As Tijuana feminist theorist Sayak Valencia has rightly argued in her book Capitalismo Gore, we must leave behind the idealised notion of the Third World masses of peasants as a necessary force of resistance. ${ }^{9}$ On the contrary, the sudden economic changes in the countryside have converted this force into the cradle of a new peasant culture in which misery and humiliation transform traditional machismo into a kind of consumerist violence. This leads to a situation where individuals who have been stripped of their ways of life and their dignity join the mafia as a way to restore a threatened masculinity, 'turning the position of parodic subalternity historically assigned to them'.10 As a consequence, Valencia concludes, 'they search for their dignity and identity affirmation ... through a kamikaze logic. Those subjects will no longer die or kill for a religion or for a political statement but for power and money.'11 As Valencia rightly suggests, we ought to consider the extreme violence of gore capitalism as an attempt to achieve immediate consumerist satisfaction by means of extermination. This happens within a new subjectivity that understands murder 'as an exchange, extreme violence as a tool for legitimacy, and the torture of bodies as sport and as a very profitable display of power'. ${ }^{12}$

This entire process lurks beneath the dust of memory collected by Aragon's stories. Against the mainstream stereotypes that tend to visualise the changes produced by globalisation in terms of the production of new urban intensities, Aragon makes us aware of the complex instability of the countryside as its borders are put into question by the forces of the present. Thus, the anxiety that one feels in Aragon's installation Tinieblas (2009) for which thirteen musicians were filmed on different days playing a funerary march by Guatemalan composer and musician Jose Arce. Standing on one of the mojoneras or boundary stones of the Ocotlan town, each musician played the tune with their respective instrument. According to the artist, the work is a reflection on the constant border conflicts that mark the history of his hometown and 
the history of different communities in Oaxaca. The image the work creates operates as a symbol of masterful ambivalence. The extraordinary orchestration of this ghostly performance, whose multi-channel experience places the audience in an imaginary centre, is a testament to a refined ambivalence wherein a new cultural dexterity appears in the midst of a maelstrom of old and new social catastrophes. This is, in fact, the condition of the New South, whose inclusion cannot be defined with the language of cultural justice and fair representation, but rather with the terms put forth by the fateful intrusion of the messengers of ethical and social disaster.

III

In the last years, the already politicised artistic practice in Mexico has had to be redefined to absorb a veritable inferno. No matter the occasional attempts to criticise it, the contemporary art scene seems to have found in the current crisis of violence the space for multifarious visual experimentation. What is surprising is the timeliness of the response: few other moments of cultural production in the history of the country have been as intimately related to the temporality of the nation.

Reviewing just a few examples might allow you to see the proliferation of the themes, as well as the variety of artistic modalities involved in the phenomenon. In most cases, we have a situation where a certain set of methodologies have absorbed a new historical situation. Thus the work that for more than a decade Argentinian-Mexican artist Enrique Jezik has been doing with firearms, acquires now a horrible urgency, a historical allegorical function. When he produced a sculpture for his overview at MUAC Museum, he modernised the medium by turning from poor materials to exploring the sculptural possibilities of bulletproof steel. By titling his recent shooting sculpture Festival of Bullets (2011), an allusion to a chapter of the famous chronicle of the Mexican Revolution by Martin Luis Guzmán The Eagle of the Serpent (1929), he suggested the tension between the materiality of protection and the new form of what at the end of the day is a revolutionary process and a subaltern rebellion. Carlos Aguirre, a key artist who has been working in the field of 
text and graphic conceptual art since the 1970s, has recently turned his research to underlying the relation between name and image in the press; for instance, comparing the nicknames of the gangsters in the underworld mafias and the image of their bodies as they are reported in the press when killed. Just recently, artist Carlos Amorales, who has had significant international attention in relation to his complex exploration of graphics, identity and cultural circulation, felt the need to use an artificial unreadable graphic alphabet he has created through different processes of abstraction, to simulate a popular photonovel where corpses borrowed from illustrated publications seem to come back to life in a gothic parallel world.

Young artist Xochitl Munguia has developed a remarkable graphic method to develop images in the street by collecting the dirt from the soles of pedestrians. She printed images of corpses selected from the press, with contact glue transferred into the paper by means of silkscreen. By gluing those potential prints on the floor in a pedestrian street in Mexico city downtown, she confronted the audience with the images of death that are imprinted already in their imaginary. Such a method was both a means to infuse life in graphics, by far the most outmoded of the traditional media, at the same time exploring the unconscious and widely extended relationship in the Mexican imaginary between corpses and trash and dirt, which comes all the way from Luis Buñuel's Los Olvidados (1950).

I would not be qualified to dismiss all those actions, objects and images as the expression of a mere wish to fulfil the needs of the international market of cultural stereotypes, for even not being an artist, I was recently carried by the urgency of producing a work. To increase my shame it is a large silkscreen print with a deliberately pretentious title, Towards an Architecture: a postindustrial anamorphism (Apres Salvador Dali), signed with artist-theorist Mariana Botey. It shows the effigy of two ziggurat-like towers, one printed in green like the US dollar bill, and the other in the purple ink of the Mexican 500 peso banknote. In presenting this work in an exhibition, without intending to violate the rules of curatorial ethical behaviour, we were arguing that the image of these twin towers was one of the few occasions where the spectre of capital 
CUAUHTÉMOC MEDINA: SEEING RED

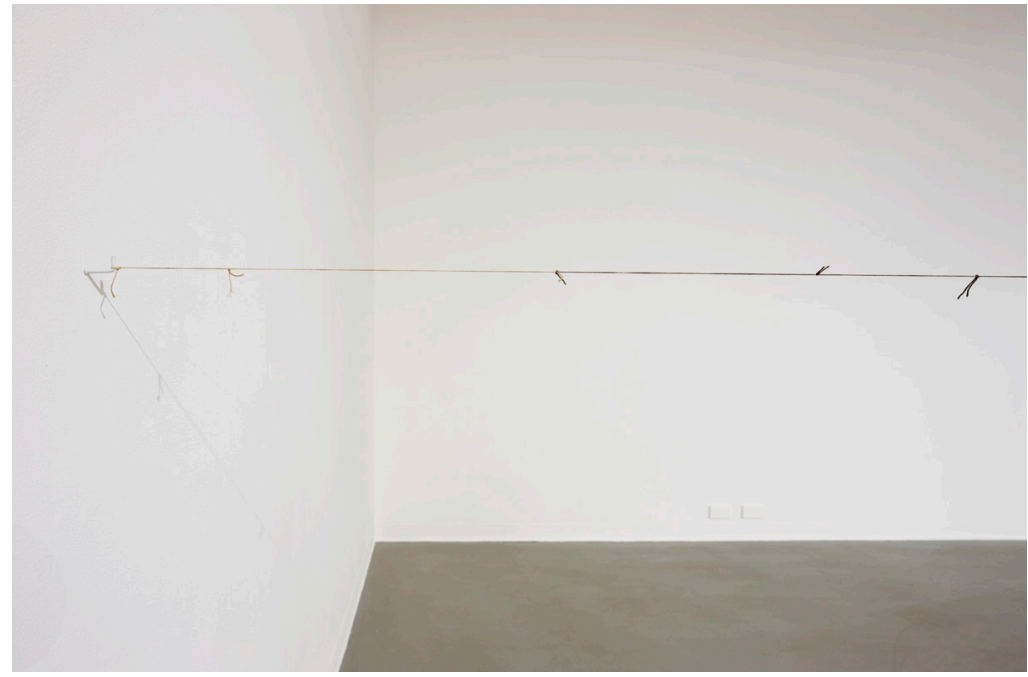

4 Teresa Margolles 127 cuerpos, 2006 
ART IN THE GLOBAL PRESENT

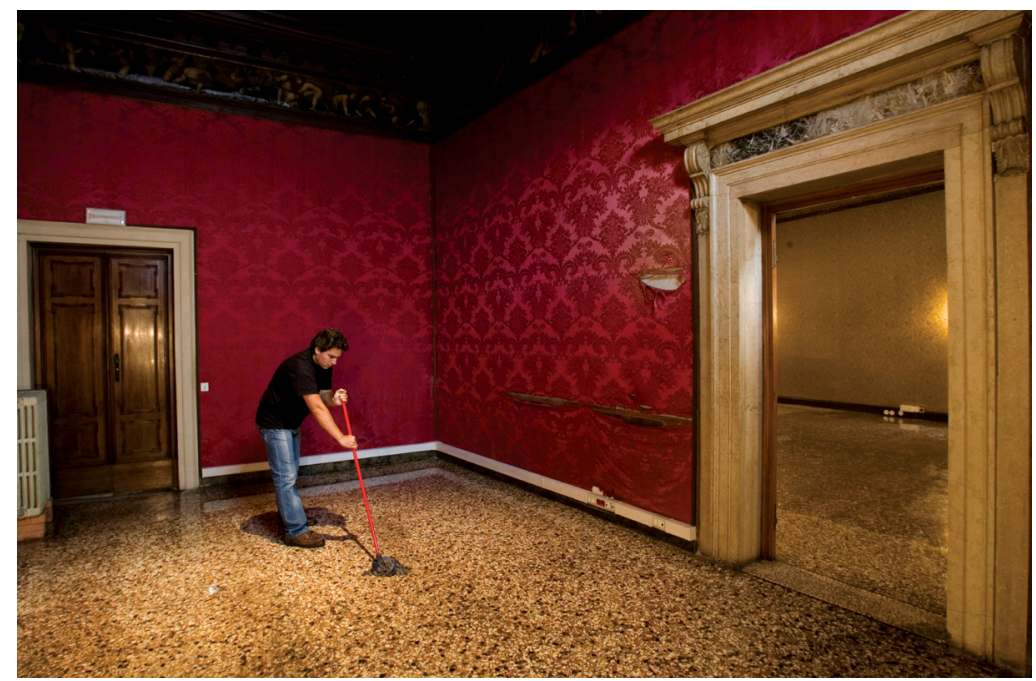

5 Teresa Margolles

What Else Could We Talk About? Cleaning, 2009

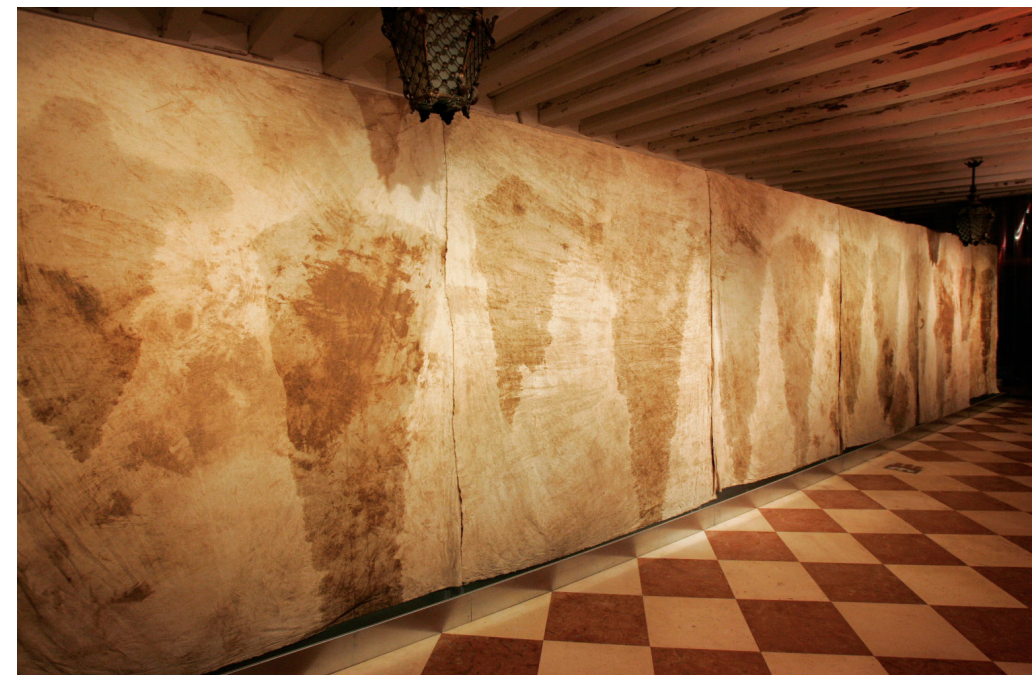

6 Teresa Margolles

What Else Could We Talk About? Recovered Blood, 2009 
could be actually presented, thanks to the collaboration of the criminal gangs and the installation art talents of the Mexican police. The idea is that, after a while, you are able to notice that these towers are a paranoiac critical image coming from a famous press photograph about the biggest seizure of cash in history: the more than \$US205 million confiscated from the Chinese businessman Zhenli Ye Gong in his office in Mexico City in March 2007. I rotated this ninety degrees to one side to reveal a hidden secondary image, very much like Dali did in 1927 in a famous contribution to 'Surrealism at the Service of the Revolution'.

Should we dismiss all these forms of cultural practice and public mirages and hallucinations, as purely opportunistic, in terms of creating a social imaginary able to grasp the span of attention of the market or the international art world, without any specific political value? I would entirely disagree. They come, in fact, from the potential criticality of the 'we' inscribed by the nation, which forces us to belong to a certain geography of discourses, and thus also sets up the space where criticality is bound to take place, at least while we do not produce a proper postnational sphere to redirect the need of building a certain kind of social and political agency. But I will argue this from within the story of a title.

\section{IV: A title}

In 2009 I was commissioned to curate Teresa Margolles's What Else Could We Talk About? intervention for the Mexican Pavillion in the Venice biennale. The process leading to the project was all but simple and straightforward. I was surprised that sometime in the middle of December 2008, just before the Christmas holidays, a letter from the Mexican Foreign Affairs Ministry arrived inviting me, with another seven curators, to make proposals for an exhibition including one or several artists, to be chosen by a panel of colleagues and museum directors. The method meant a significant institutional advance. For the first time an official event of cultural exportation, which had all through the twentieth century had been defined by the ideological agenda of the powers that be, could be up for grabs for a critical intervention. I would argue that the method alone created a field of immanency. 
I immediately set on the artist that I would want to work if chosen: Teresa Margolles. By the end of 2008 Margolles was still relatively marginal in the global art circuit. She had been working for two decades in relation to human remains, both as member of the Semefo (the Medical Forensic Service) collective in the early 1990 and as a soloist. Yet, she and the fearsome thematic and materiality of her work made it hard for curators and institutions to take her on board. Beyond such issues, what made her a self-evident choice was a specific political turn in her daunting poetics. From 2007 onwards, Margolles had abandoned her idiosyncratic atelier in the official mortuaries of Mexico to explore the pervasive presence of death in the urban and social landscape. (Figure 4) This had, evidently, been over-determined by circumstances: her gothic aesthetic had been forced to address a crisis of overproduction. In our exchange of ideas via email in the winter of 2008 (we were in fact located at the opposite sides of the Mediterranean Sea, she in Madrid and I in Beirut) Teresa described in her own words the plight she felt it was necessary to address:

I am interested in talking about what is happening in the State of Sinaloa. There are 1120 dead this year and December is not finished ... each month the figure is bigger than the previous month ... These are 1120 people, mostly youngsters, who do not exist anymore and, corny as it may sound, will not be with their families on Christmas. There will be only empty chairs, and their memory that in these cases becomes vendetta. To revenge the brother, cousin, the friend or one's own son ... I am also working about the sense of blood ... On who is cleaning the blood from the street, and about the hundreds of score settling shootings, shot bodies... with clothes impregnated with blood, not any longer in the morgue during necropsy, but blood directly retrieved from the floor where, once the corpse is taken, it stays like a trace, as a last refuge. I do not need any longer to go to the morgue because the bodies are lying in the street.

This was, indeed, a situation where the heterotopic had become topical, bringing an underground cultural practice 
to produce its necrology in broad light. The project Margolles and I arrived at by the first days of 2009 involved employing strategies of low materiality exportation to explore the way violence has inundated the streets of cities in the north of Mexico with corpses. At this time it was still possible for the government to pretend that the violence crisis affected only members of the criminal gangs, adhering to the indifference with which mainstream society stares at the extermination of those who, well beforehand, had implicitly been deemed disposable. By 8 January 2009, we had finished the project but we were still lacking a title for the show. Fortune is an ironical goddess, as you may well know. I had just landed back in Mexico City, when Teresa called me over the phone urging me to check La Jornada newspaper. In the first page one could read the following item:

The Diplomatic staff ought to point out that there is no chaos: Calderón

Claudia Herrera Beltrán

President Felipe Calderón instructed ambassadors and consuls to spread out the reality of the country, because it is not true that the 'civil population is being massacred in the streets' of Mexico and that chaos prevails.

He admitted the number of casualties was surprising and worrying, but claimed they are indissolubly bound to the battles of criminal groups for territories they are losing, and related to the weakening of their structures. Therefore, he recommended them to claim proudly that the country lives a moment of institutional recomposing and that it enjoys democratic stability.

I was taken aback. In other days when a Mexican president would dictate an ideological line ('dar línea') in such an emotional way, they would at least abide by the unwritten good manners rule of keeping everything in the dark and instructing his employers to stay away from the view of journalists. I grabbed the phone, called the artist, and told her in a rather defeatist tone: 
'Look, Teresa: the president is instructing the ambassadors to silence the information about violence in the country, so it is unlikely that a project like the one we just made will be chosen. My gut feeling is that we should simply radicalise the project knowing that we will be working for the archive files, and just try to produce the show locally. I mean that we would at least leave the idea in the record.'

Angry on the other side of the line, I heard Teresa saying:

'No way: what do they think they are. What else could we talk about?'

I stopped her:

'Tere: that's it. There you have the title: "What else could we talk about?"”

I believe this story may help illuminate the way contemporary art in places like Mexico is frequently entangled in a programmatic or unconscious symbolic battle with the discourses of power. The coming together of different agendas is bound to produce friction and disagreement. In Margolles's interjection one can attest to the way a number of contemporary artists involve their work in a certain intervention of the sphere of public representations and words. Despite the erosion of the role of the public intellectual under global capitalism, artists like Margolles, in precisely not considering themselves as 'political' practitioners, assume a wider role in strategically conducting their material and symbolical practices as an intervention in relation to the very fabric of the public sphere. The questioning of what is meant to appear and be perceived, of which lives and deaths are considered a matter of concern, on which forms of living and dying are meant to be conceived by the common sense. In fact, this title encodes, in my view, the betraying theory of the current artistic situation: the impossibility of limiting this speech, at the same time one has to confess the burden involved in carrying it. And the unavoidable political conflict springing from the impossible goal of an administration that unwisely believes that both the 
social situation, and the discourses emerging around it, are to be contained for the sake of the image of the nation within the field of representations that constitute the global imaginary.

This instability of images is very much at the core of the case. To the distaste of government officials, by 2008 global news agencies had started to report on the uncontrollable violence. They had been particularly offended when back in March 2008 one of the darkest American intelligence thinkthanks, STRATFORD, which by the way has recently been at the centre of a significant Wikileaks exposure, warned that Mexico, with Afghanistan, was in danger of collapsing into anarchy, claiming that it was nearing the status of a 'failed state'. Such a claim, misinterpreted by the press and the political class as if it were coming from the American military and intelligence agencies, left a painful scar on the forehead of an elite entirely convinced that such an international image has effects not only in terms of political stability but also in relation to the country's suitability for tourism and foreign investment.

The geography of images is that important. The great obsession of the neoliberal elites around the world is, indeed, the way the behaviour of markets and polls seem to be inextricably bound to the volatility of images and expectations. This is to say that, in a twisted version of what in physics we call the Heisenberg principle, the way the south is perceived by the north appears as creating the south, defining both its markets and its self-representation, to a point that, as has also occurred with the Greek financial crisis, overrules any principle of democratic management or any concept of sovereignty.

In turn, Margolles's show was a careful negotiation of theatrical expectations, political allusions, carefully staged silences and trust in the emotional and conceptual significance of intimacy with base materiality. A great deal of the effect of the exhibition involved the different ways the artist enacted a ghostly materialisation of the uncanny presence of the bodies of the dead. Margolles's first decision was to absorb the dirt and ruin of the Rota Ivancich by refusing to clean or restore the rooms of the sixteenth-century Venetian palace selected as the venue for the Mexican Pavilion. She was intending to absorb the dust and residue of the place, and mix it with the 
import of contemporary dead matter. Secondly, there was the dutiful production of a number of rules devised to create decorum for a process of mourning. No parties were allowed in the pavilion; furthermore, artist and curator, and any other person, were strictly prohibited from guiding tours or individuals into the building. The work was meant to operate as a matter of direct experience, rather than being framed as a statement of intent. All interaction with the site and works was to be trusted to the discreet labels providing the minimum information to trigger the experience. The work, properly speaking, was to take place as a matter of resonances and contaminations, both at the level of the metonymic contact of the bodies of the dead and the living, and the imaginary geography produced by the geographical transference of the gothic spatiality of dying.

I will only sketch the workings of the two main projects of the exhibition. After walking through a number of empty rooms, the audience would encounter a quiet action or evidence of it in the guise of moisture on the floor. Performers, some of them in fact activists from the Mexican border in the north, who knew from direct experience the tragedy of their cities, were meant to quietly and ceremonially mop the floor, leaving a minimum trace of water. After a few rooms, the audience would encounter a text on the wall explaining the peculiarities of the rite. At least once a day, for the duration of the biennial, the floors were mopped with water containing a minimum quantity of blood from people killed in the north of Mexico. (Figures 5 \& 6) Through the six months of the exhibition, this ghostly matter was meant to impregnate the building and also, in minimum traces, the shoes of the audience. Margolles invoked the presence of people killed by means of a small quantity of their body fluids, carried by water, mud and clothes, those materials gathered from the floors where killings had been performed. Dirt with dirt, matter with matter, dust against dust and water and mud, all those combinations and permutations were to both invoke a response from the viewers and document the condition of an impossible geography of the present. In that sense the exhibition appears as a summary of the strategies of the undercover exportation of dead materiality with which Margolles, in recent years, has 
devolved to the privileged north (geographically speaking as well as socially and economically) the deadly costs of their exploits. Such microscopic, invisible and symbolic exchange was furthermore underlined by a critical gesture. As you may know, it is a tradition of the biennial to raise the flag of the country of each pavillion next to that of the European Union and the emblem of Venice. The gesture, which again involved enormously complex negotiation and conflict, replaced the Mexican flag with a blood soaked piece of cloth. The emblem of a death territory, the signature of a geography of neocapitalism.

As I have told you, the title of the Mexican Pavilion of 2009 encoded a retort to the administration's intention to deny such transmogrification of the national geography. When Margolles and I were selected, all hell broke loose behind closed doors. Alerted about the presidential orders, the Ministry of Foreign Affairs requested some time, which was employed by one of the candidates to use her ministerial connections to have the decision changed. It took two weeks at least until the officials from the Fine Arts Institute convinced Foreign Affairs that the costs of censoring the work would be much more damaging than letting it happen. A wise bureaucracy, indeed, would have tried to cash in on the democratic gesture of absorbing it. It did not work that way. If you check the material published at the time of the biennial, the logo of the Mexican Foreign Affairs Ministry disappeared, along with that of the Jumex collection. Both withdrew in silence, with an absolute disdain for the commitments they had taken in public. By time of the biennale there was literally no Mexican officially present to represent the government in the Pavillion, not even the cultural attaché to Italy. Margolles's exhibition went on as representation without representation, as an official pavillion with no official representatives.

Now that Felipe Calderon's administration is over, I finally feel free to say that Margolles's project caused a number of internal casualties: one of the members of the jury, the Tamayo Museum director, Ramiro Martinez, had to step down from his post because the pressure from one of the losing candidates made his position untenable. Similarly, the head of the cultural section of the Foreign Affairs Ministry, Alberto Fierro, 
who had initiated the project, was quietly removed from his post and be transferred to a Mexican consulate in Florida, which seemingly is the equivalent of Siberia for the Mexican foreign service. All attempts to stage the action back in Mexico City, first in a the Carrillo Gil Museum, and then in 'Crisisss', an exhibition by Gerardo Mosquera in the Fine Arts Palace of Mexico City, were aborted in fear of infuriating the higher authorities. Totally independent projects related to tracing the social and cultural effects of drug dealing in culture became suddenly dangerous for the art institutions, that feared that they would wake up the spectre of the Venice Biennial. But all those costs were worth it. They come to suggest that, differently from what many critical arguments seem to believe, art remains political because all the time, even unconsciously, we are responsible, as much as the elite and the media apparatus that communicates propaganda, for the representations that build the hegemony. In essence, our means and mute methods are not as devoid of power and significance as they intend us to believe. All that is to be understood once one does not escape from the condition of art-making in the south, which involves accepting a certain complicated negotiation with the historical situation that is imposed on us. Because we are constituted by the imaginary community of a 'we'. The 'we' that is stated when we say things like 'What else could we talk about?'

\section{V: Outburst}

Do not expect, however, that the efforts of activating a political space of artistic interventions in the south will be devoid of paradoxes and conflict. One of the main difficulties we have is incorporating this different geography of the political into something like a common front, which arises from the impossibility of a multiculturalist administrative policy that could also address the specific and sporadic outburst of a southern political aesthetic. Just last week Teresa Margolles's show at the Dowse Art Museum in Lower Hult, New Zeland, which was going to include her action So it vanishes, consisting of the emission of soap bubbles made with a small proportion of water used to clean corpses of people who had died in violent circumstances, was cancelled because of objections raised 
by the Maori. According to the press, local Iwi in Lower Hult argued that Margolles's work with fluids from dead bodies was 'equivalent to inviting death or calamity'. Within such a narrative, of course, it would be logical to jump to the conclusion that, after all, maybe the work of artists such as Margolles in Mexico are to be blamed for the current social situation. We ought to give Maori the benefit of the doubt. Inasmuch as works like these involve, in their methodologies, the figure of the nomadism of the current geographies of capitalism, and they suggest the impossibility of containing the geographies of death in their apparent point of origin, indeed, the arrival of works like Margolles's could mean that the spaces of calamity will not just remain over there.

\section{Notes}

G. Saldierna and K. Avilés, 'Con un mural en la frontera, Calderón exige a EU detener el tráfico de armas', La Jornada, 17 de Febrero $2012<$ http://www.jornada. unam.mx/2012/o2/17/politica/o13n2pol>.

2 Líbera, an Italian human rights organisation, reported in December 2012 that the actual death toll of the 'invisible and absurd war' on drugs by President Calderón's administration is 136,100 people, a number well above any casualty of a war in recent times around the world. A. Méndez, 'Documentan más de $136 \mathrm{mil}$ muertes por lucha al narco; "más que un país en guerra", La Jornada,11 December $2012<$ http://www.jornada.unam.mx/2012/12/11/politica/o15n1pol>.

3 Comité Invisible Jaltenco, 'La estética relacional del calderonato: pedagogía condescendiente', 23 February $2012<$ http://comiteinvisiblejaltenco.blogspot. $\mathrm{mx} / 2012 / 02 /$ el-calderonismo-como-estetica.html $>$.

4 Ibid.

5 P. Reyes, Palas por Pistolas Manifesto <http://www.palasporpistolas. org/?page id =162>. For an account of this work by the artist see $<$ http:// pedroreyes.net/palasporpistolas.php $>$. For a presentation on the different actions and exhibitions Reyes has produced on the basis of the shovels, see $<$ http://www. palasporpistolas.org/>.

6 See $<$ http://www.santiago-sierra.com/200704_1024.php $>$.

7 A. Mbembe, 'Necropolitics', Public Culture 15, no. 1 (2003): 40.

8 In August 2012 the corpses of 72 Central American immigrants were found in a mass grave in the municipality of San Fernando in the Mexican State of Tamaulipas. According to one of the survivors of the massacre, the immigrants, who had been kidnapped from cars that were taking them north toward the US border, were killed because they could not pay their ransom and because they resisted joining the Zeta paramilitary group. Jesús Aranda, 'Zetas ejecutaron por la espalda a 72 migrantes', La Jornada, 26 August $2010<$ http:// www.jornada.unam. $\mathrm{mx} / 2010 / 08 / 26 /$ index.php?section $=$ politica\&article=0o) $2 n 1 p o l>$. Since then it has become common for mass graves to be discovered throughout the country while numbers of missing people has increased rapidly, to, according to the National Commission of Human Rights, more than 24,00o. See Olga Rodríguez, 'Unidentified bodies, missing cases mount 
in Mexico,' Associated Press, 23 July $2011<$ http://bigstory.ap.org/article/ unidentified-bodies-missing-cases-mount-mexico $>$.

9 S. Valencia, Capitalismo Gore (Madrid: Melusina, 2010).

10 Ibid., 81.

11 Ibid.

12 Ibid., 85. Similarly, we ought to interpret the military deploment of Felipe Calderon's administration (2006-2012) as a failed attempt to repair lost male authority. 